\title{
CONRADO DEL CAMPO (1878-1973) Y SU CONCEPCIÓN DEL DRAMA LÍRICO EN EL FINAL DE DON ÁLVARO (1910)
}

\author{
Víctor Cantero García \\ Universidad Pablo Olavide \\ cantero91@hotmail.com
}

\begin{abstract}
RESUMEN: En este articulo abordamos una de las cuestiones que evidencian más a las claras la provechosa relación que puede existir entre el drama romántico y el teatro lírico, cuando el texto dramático es la fuente que inspira la composición del libreto y de la partitura de una ópera homónima. Tal es el caso del drama del Duque de Rivas, Don Álvaro o la fuerza del sino (1835) y la ópera de Conrado del Campo, El final de Don Álvaro (1910).

Conrado del Campo, uno de los compositores españoles de ópera más relevantes de comienzos del siglo $X X$, supo descubrir en los elementos musicales existentes en el texto dramático de D. Ángel Saavedra el germen de su primera ópera. Así, mediante la inteligente combinación de los postulados musicales wagnerianos con los ingredientes pasionales propios del drama tardorromántico alumbró su propio modelo de ópera nacional, siempre vinculado a los elementos singulares del folklore hispano.
\end{abstract}

PALABRAS CLAVE: Conrado del Campo, drama romántico, teatro lírico, ópera nacional.

\section{CONRADO DEL CAMPO (1878-1973) AND HIS CONCEPTION OF THE LYRIC DRAMA IN THE END OF DON ALVARO (1910)}

ABSTRACT: The present paper is focused on one of the issues that most clearly show the fruitful relationship that can exist between romantic drama and lyric theater, when the dramatic text is the source of inspiration for both the libretto and the score of a homonymous opera. Such is the case of the drama of the Duke of Rivas, Don Alvaro or the force of fate (1835) and the opera composed by Conrado del Campo The end of Don Alvaro (1910).

Conrado del Campo, one of the most important Spanish opera composers of the early twentieth century, was able to discover in the musical elements existing in 
the dramatic text of D. Angel Saavedra, the germ of his first opera. Thus, through the intelligent combination of Wagnerian musical postulates with the passion ingredients of late-Romantic drama, he illuminated his own model of national opera, always linked to the singular elements of Spanish folklore.

KEYWORDS: Conrado del Campo, romantic drama, lyrical theater, national opera.

\title{
CONRADO DEL CAMPO (1878-1973) ET SA CONCEPTION DU DRAME LYRIQUE À LA FIN DE DON ALVARO (1910)
}

\begin{abstract}
RÉSUMÉ : Dans cet article, nous abordons l'une des questions qui montrent le plus clairement la relation bénéfique qui peut exister entre le drame romantique et le théatre lyrique, lorsque le texte dramatique est la source qui inspire la composition du livret et la partition d'un opéra homonyme. C'est le cas du drame du duc de Rivas, de Don Álvaro ou de la force du destin (1835) et de l'opéra El final de Don Álvaro (1910) de Conrado del Campo.

Conrado del Campo, l'un des compositeurs d'opéra espagnols les plus importants du début du XXe siècle, a pu découvrir dans les éléments musicaux existant dans le texte dramatique de D. Angel Saavedra le germe de son premier opéra. Ainsi, par la combinaison intelligente des postulats musicaux wagnériens avec les ingrédients passionnés typiques du drame romantique tardif, il a illuminé son propre modèle d'opéra national, toujours lié aux éléments uniques du folklore hispanique.

MOTS CLÉS : Conrado del Campo, drame romantique, théâtre lyrique, opéra national.
\end{abstract}

Recibido: 16/04/2020. Aceptado: 04/10/2020

\section{Introducción}

Después de leer el siguiente comentario relativo al éxito cosechado por Conrado del Campo con el estreno El final de Don Álvaro (1910):

... the composer Conrado del Campo (1878-1973) and his first opera, El final de don Álvaro (1910), which epitomizes the moment at which the pressure to include Wagnerian style within Spanish opera was at a peak. He was, together with Falla, one of the most important composers at the time, not only because of the inherent quality 
of his prolific catalogue, but also because of the influence of his aesthetic ideas on his students of the Conservatory of Madrid. Altough he performed only twice, this opera, premiered at the Royal Theater of Madrid in 1911, had an excelent critical reception. (Ferreiro 2018)

pensé que poco más se podía decir acerca del buen tino de este músico español a la hora de elegir el Don Álvaro o la fuerza del sino (1835) como fuente de inspiración para la composición de la que fuera su primera ópera. Sin embargo, tras reflexionar sobre tamaño acierto me incliné por pensar que algo más se podía añadir sobre el mismo, pues en modo alguno me parecía fortuito, y mucho menos tras conocer esta aportación de Loreto Busquets relativa a los recursos expresivos con los que el Duque de Rivas dotó a los versos de su drama:

No desdeña potenciar la expresividad del texto con recursos que pertenecen a las demás artes: a los de la pintura en los grandes lienzos descriptivos de su obra, y a los de la música en la expresión de sentimientos y emociones sintéticamente inefables. Ello en una visión unitaria y comunicante de las artes, con la que nuestro dramaturgo se revela no solo portador, sino anticipador, de las ideas más innovadoras del Romanticismo. (Busquets 1989: 438)

Efectuada una lectura en clave musical de dichos versos, comprobé, efectivamente, que el dramaturgo los impregnó de recursos musicales. Tal constatación me motivó a averiguar si Conrado del Campo se percató de la musicalidad del texto dramático de Rivas y en consecuencia apostó por este drama y no por otro para componer su ópera ${ }^{1}$. Esta es la primera cuestión que abordamos en la presente colaboración: demostrar que los versos del drama elegido por nuestro autor están dotados de una riqueza melódica y una variedad rítmica capaces de constituir un conjunto de secuencias tonales, en base a las cuales Del Campo pudo componer con más facilidad la partitura de El final de Don Álvaro (1910).

1. No cabe duda de que Conrado del Campo conocía otros intentos similares, tal es el caso de la ópera de Giuseppe Verdi titulada La forza del destino basada en el mismo drama del Duque de Rivas y estrenada en San Petersburgo en 1862, así como una nueva versión de la misma de 1869, en la que Verdi modifica el acto final de la anterior, evitando el suicidio del protagonista. Sin embargo, Del Campo no optó por el modelo musical verdiano y además no evitó en su obra el trágico desenlace con el que Don Álvaro pone fin a su vida. Nuestro autor se inclina por los postulados musicales wagnerianos, implementando en su ópera el wagnerismo de una forma sólida y bien asimilada, superando la mera imitación o la simple transgresión de los dictados musicales de Wagner. 
En un segundo momento nuestro trabajo intenta demostrar que Conrado del Campo se inclinó por el Don Álvaro de Rivas guiado por su gusto por el dramatismo propio de los dramas románticos del XIX. Él quería presentar ante un público de comienzos del siglo XX una ópera en la que se evidenciase su predilección por los modelos dramáticos del tardo romanticismo, los cuales se prestaban con mayor facilidad a poner en práctica los paradigmas musicales wagnerianos. Además, su inclinación por el drama de Rivas obedece a que Del Campo encuentra en él los tintes propios de nacionalismo folklorista con el que pretende dotar a El final de Don Álvaro, pues a su juicio El Don Álvaro contiene:

El carácter adecuado, castizo, propio que era preciso imprimir a la orquestación durante toda la obra, pero más aún en las escenas intercaladas de «sabor popular» que debían ofrecer con un marco de sabor local, de ambiente español, «serrano», el dramático asunto del poema.

(Del Campo 1911)

En esto consiste nuestro segundo reto, a saber: poner de manifiesto hasta qué punto Conrado del Campo fue capaz de captar los valores literarios propios de un drama romántico y trasladarlos al canon musical wagneriano, sin olvidarse de añadir los tópicos populares hispanos que dotasen a su obra del españolismo propio con el que debía contar la ópera nacional frente a los modelos operísticos importados.

Una vez que Conrado del Campo tuvo claro su propósito de componer una ópera que se ciñera a las características antes mencionadas, acudió en busca del libretista que mejor pudiera plasmar las mismas en el libreto que le encargase. Y encontró en Carlos Fernández Shaw a la persona adecuada. Los motivos que justifican esta elección constituyen el tercer asunto al que dedicamos nuestra atención en el presente estudio. Conocía Del Campo el éxito de los libretos de Fernández Shaw para las obras de Ruperto Chapí y no dudó en solicitar su colaboración. Este afamado libretista volvió a dar la talla con su texto para El final de Don Álvaro. Sin entrar en un análisis comparativo de la calidad literaria de los versos del Don Álvaro y los del libreto para la ópera de Del Campo, nos detenemos a considerar si los cambios introducidos en la Jornada $\mathrm{V}$ del drama de Rivas por Fernández Shaw fueron los más idóneos para implementar el proyecto de drama lírico ideado por Del Campo.

Compuesta la ópera tan solo quedaba comprobar si la misma contaría con el aplauso del público y el respaldo de la crítica. Este es el cuarto tema que abordamos en la presente colaboración. ¿Se estrenó la obra en el momento más adecuado? ¿Cuáles fueron los comentarios de la prensa periódica antes y después de su estreno? ¿Cosecharon Del Campo y Fernández Shaw el éxito deseado? 
¿Consiguió del Campo afianzar la ópera nacional gracias al éxito cosechado con El final de Don Álvaro? Estas y otras tantas cuestiones son atendidas en el cuarto apartado de nuestro trabajo, el cual finaliza con las conclusiones.

\section{La musicalidad subyacente en el texto del Don Álvaro o la fuerza del sino, del Duque de Rivas}

Dos eran las cualidades que Del Campo buscaba en los versos del drama de Rivas: que contasen con las secuencias tonales y melódicas necesarias para poder ser cantados en un foro operístico, a la par que pudieran ser trasladados a una partitura compuesta según sus gustos musicales wagnerianos, y que contasen con el final trágico propio de los dramas tardorrománticos que a él tanto le agradaban. Un desenlace que además podía ser ubicado entre escenas de neto sabor popular con las que reivindicar el nacionalismo folklorista propio del modelo de ópera nacional que él postulaba. Un canon de drama lírico que según lo apuntado por Alberto Sánchez «iba contracorriente, pues, justo en aquellos momentos la crítica de la Generación del 98 hacia los dramas románticos, encarnada en Azorín, era desfavorable» (Sánchez 2010: 33). Azorín somete al Don Álvaro a una disección analítica de signo racionalista y rigor implacable, y pese a que reconocía en alguna escena de este drama: "un hálito de grandeza, de honra y vibrante tragedia" para él, en general, "el drama del Duque de Rivas es una lógica, natural continuación del drama de Calderón y Lope. Son los mismos procedimientos, la misma falta de observación, la misma superficialidad" (Martínez Ruiz 1916).

Sin embargo, por encima de los juicios desfavorables de la crítica, Conrado del Campo persiste en su intento de lograr que su ópera El final de Don Álvaro, al que califica de poema escénico, sea:

Una pieza que resuma y sintetice la acción romántica y vigorosa del drama famoso del Duque de Rivas, una de las obras del pasado siglo en que mejor se refleja y caracteriza el carácter legendario de nuestra raza con sus arrebatos, sus desalientos, sus impulsos de pasión desbordada, que por encima de la razón salta, osada, insensatamente, hacia un ideal confuso que se oculta allá en la mente heroica, en el sacrificio que redime. Obra extraña cuyo Final causóme siempre honda impresión y en el que hallé elementos poderosos de musicalidad, dentro del marco escénico. (Del Campo 1911: 9)

¿Dónde se encontraban esos poderosos elementos de musicalidad? No cabe duda que Del Campo conocía que algunos de los dramas románticos más 
representativos como La Conjuración de Venecia, año 1310 (1830), de Francisco Martínez de la Rosa; El Trovador (1836), de Antonio García Gutiérrez o Los amantes de Teruel (1849), de Juan Ignacio Hartzenbusch contaban con versiones musicadas, tal como nos precisa Marina Barba, durante el periodo romántico teatral la situación cambió sustancialmente, pues:

Los dramaturgos, en largas y detalladas acotaciones, explicaban dónde y con qué intención dramática debía haber una intervención musical. A su disposición estaba el maestro compositor, quien intentaba reflejar musicalmente con la mayor exactitud esas directrices dramáticas a través de las composiciones. El texto y la música eran una unidad resultado de un proceso creativo global, susceptible además de modificaciones y mejoras según fueran avanzando los ensayos e incluso a lo largo de las representaciones. Un buen número de las intervenciones musicales eran canciones cuya letra estaba escrita por el dramaturgo. Este hecho marcaba las pautas de composición porque obligaba a que los acentos musicales coincidieran perfectamente con los de las palabras para permitir una buena comprensión del texto. Para que se transmitiera correctamente el sentido de los versos era necesario escoger acertadamente la melodía, la armonía, la forma, el ritmo y el fraseo de la pieza. La colaboración entre el compositor y el dramaturgo era fundamental también para establecer una relación lógica entre la música y la acción, así como delimitar perfectamente la duración de las intervenciones. (Barba 2013:131)

Por el contrario, El Don Álvaro carecía de las mismas. Por eso del Campo se decidió por hacer una versión musical de este drama, pese a lo complejo que resultaba musicar un texto con tantos personajes, numerosos cambios de escenario, complicaciones en la acción y tantas muertes en escena. Su primer cometido consistía en localizar los recursos musicales con los que contaba este texto dramático, a los efectos de que los acentos musicales coincidieran perfectamente con los de las palabras para poder transmitir correctamente al público el sentido de los versos. Una coincidencia que le obligaba a examinar con tiento la melodía, la armonía, la forma, el ritmo, el tiempo, la intensidad y la sonoridad de los versos de Rivas. Dicha localización le exigía un profundo análisis y un estudio detallado tanto de las estructuras estróficas y de la métrica de los versos, como de los esquemas musicales y la disposición rítmico-melódica de las palabras dentro de cada verso, pues:

La palabra poética además de ser portadora de significantes, se estructura en sonoridades, en secuencias rítmico-melódicas [...] por lo que la determinación y el análisis de los prosodemas y de los periodos rítmico-melódicos parten siempre del tema y del tono emocional poético, pasando por la estructura morfosintáctica, determinante en la andadura del verso. Todo ello 
conlleva descifrar una música verbal, sea que se trate de un juego aliterativo, de una línea melódica ascendente o descendente, de un acelerando o de un ritardando, de una secuencia débilmente o intensamente marcada, de un legato o de un staccato. (Busquets 1989: 436-437)

Procedemos a continuación a recorrer el mismo camino que anduvo en su día Del Campo para demostrar, mediante una serie de ejemplificaciones, que Rivas escribió los versos de su Don Álvaro dotándolos de cadenas fónicas propias de la lengua poética, a la par que esenciales para el trazado melódico que debe caracterizar a la recitación más o menos enfática y a la velocidad que deben caracterizar a la declamación de dichos versos en función de cada uno de sus intérpretes.

\section{EJEMPLO $1^{\circ}$}

(Monólogo de Don Álvaro. Jornada III. Escena III. vv. 961-980)

Estrofa $8^{\mathrm{a}}$
¡iSevilla!! ¡iGuadalquivir!!
¡Cuán atormentáis mi mente!...
¡Noche en que vi de repente
mis breves dichas huir!
¡Oh, qué carga es vivir!
¡Cielos saciad el furor!...
Socórreme, mi Leonor,
gala del suelo andaluz,
que ya eres ángel de luz
junto al trono del Señor,

\section{Estrofa $9^{\text {a }}$}

Mírame desde tu altura

sin nombre en extraña tierra, empeñado en una guerra por ganar mi sepultura.

¿Qué me importa, por ventura, que triunfe Carlos o no? ¿Qué tengo de Italia en pro? ¿Qué tengo? ¡Terrible suerte! Que en ella reina la muerte, y a la muerte busco yo (De Rivas [1835]

2010: 114)

En ambas estrofas existe un juego de líneas melódicas ascendentes y descendentes que refuerzan con eficacia la elevación de la mirada al cielo " $i C i e l o s$ saciad el furor!..." (v. 966), que además queda enfatizada por la iteración vocálica (o/o-e/e) y por la esdrújula en "socórreme" del verso siguiente, la cual pone en marcha un movimiento ascendente, en cuyo punto más alto, justo en la armonía y serenidad de lo eterno, se encuentran Leonor (v. 967) y el trono del Señor (v. 970). Desde dicha altura se inicia un movimiento descendente paulatino, para luego a partir del v. 971, que arranca marcadamente desde lo alto en virtud del acento inicial en voz esdrújula «mírame», descender hasta tocar este mundo miserable y acabar en el hoyo de la sepultura (v. 974). Estas modulaciones propiciadas por 
el ritmo melódico propio de la décima o espinela producen un esquema musical binario que se ajusta a los juegos antitéticos ocasionados por contraposiciones semánticas: vida/muerte; altura/tierra. Por otro lado, el contraste entre vibrantes múltiples de la segunda parte de la estrofa octava («rr» [r] $)$ : socórreme); («rr» [r]: trono) y las vibrantes simples de la segunda mitad de la estrofa novena («r» [r]: Carlos, suerte, muerte), incide en el mismo movimiento melódico por medio de la oscilación entre el ansia y la desesperación de Don Álvaro en "socórreme" (v. 967) y la serenidad imperturbable de Leonor en "mírame desde el trono" (v. 971). Y todo ello sin olvidarnos del contraste entre la sonoridad y musicalidad de términos como "Sevilla", "Guãdãlquivurr" (v. 961) que resuenan a felicidad y el doloroso "mis breves dichas huir" (v. 964), dejando entre ambos versos la serie


y habla de noche y tormento.

Estos vaivenes melódicos articulan un esquema musical basado en la transformación emotivo-sentimental experimentada por el protagonista, el cual pasa del recuerdo gozoso de las dichas de tiempos pasados a las amarguras de la situación presente. Por ello la melodía de este soliloquio de D. Álvaro surge de su corazón y no de su mente (v. 962), pues se trata de una expresión verbal en la que se sintetiza la esencia de la existencia humana en base a la observación y análisis de la realidad objetiva, la suya propia, y por ende la de los demás seres humanos.

\section{EJEMPLO $2^{\circ}$}

(Encuentro amoroso. Jornada I. Escena VII. vv. 241-253)

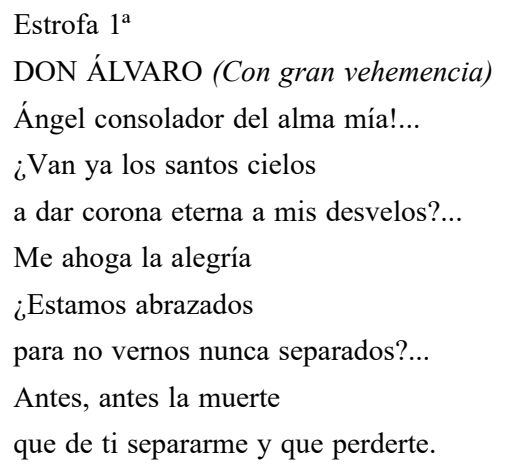

Estrofa $1^{\mathrm{a}}$

DON ÁLVARO (Con gran vehemencia)

Ángel consolador del alma mía!...

¿Van ya los santos cielos

a dar corona eterna a mis desvelos?...

Me ahoga la alegría

¿Estamos abrazados

para no vernos nunca separados?...

Antes, antes la muerte

que de ti separarme y que perderte.

Estrofa $2^{\mathrm{a}}$

DOÑA LEONOR (Muy agitada)

¡Don Álvaro!

DON ÁLVARO

Mi bien, mi Dios, mi todo

¿Qué te agita y turba de tal modo?

¿Te turba el corazón ver que tu amante se encuentra en este instante más ufano que el sol?...¡Prenda adorada! (Ibídem, 63) 
Recurre en esta ocasión Rivas a la silva para expresar el sentimiento, la emoción, los movimientos del alma y las fuerzas inconscientes que guían la conducta humana. La silva es aquí el metro de la soledad, pues el inconsciente personal es individual e intransferible. Esta combinación estrófica de versos de once y siete sílabas contiene una musicalidad que pasamos a referir. Después de la Escena $\mathrm{V}$ que describe un encuentro convencional entre Leonor y su padre, irrumpe por primera vez en escena D Álvaro, arrollando con su ímpetu y alegría juvenil, a la par que anticipa la trágica certeza de su fatal destino. Se produce por primera vez un dúo de amor mediante las silvas. El endecasílabo enfático pone en marcha con idéntica violencia un movimiento rápido y poderoso en cascada, el cual se inicia con el acento ictual que hace recaer el apoyo rítmico en la primera sílaba acentuada (ăngel) (v. 241), pasando a disparar un caudal melódico y sonoro lleno de multisonancias enérgicas y muy luminosas (ăngel consolador del ălma mŭa). El esquema silábico corre hacia el acento en la sexta sílaba, con un ritmo ininterrumpido e impetuoso gracias al tetrasílabo (con/so/la/ dor) del primer hemistiquio. El término ăngel rebota fonéticamente en ălma que porta el acento ictual del segundo hemistiquio. La pausa versal prolongada por los puntos suspensivos (v. 242) que equivale a un calderón, nos dice lo que la voz no dice y abre un suspiro y es un desahogo del alma lo mismo que lo hará el término "alegría" en el v. 244.

El heptasílabo del v. 242 forma, mediante un encabalgamiento, una unidad sintáctica con el verso siguiente, trazando una amplia línea melódica ascendente hacia los cielos que hablan de eternidad y coronación gloriosa, merced a la interrogación. Por el contrario, en el v. 244 ("me ahoga la alegría") lo que antes era expansión ascendente, ahora mediante el heptasílabo y el juego vocálico (e/a/o-a/a/a-o e/a/o) es un movimiento concéntrico marcado por la sílaba tónica en la sexta (nŭnca) en v. 246, mediante el que el poeta expresa el anhelo de que nunca exista separación entre los amantes aunque se mantenga implícita la amenaza de la muerte v. 247. Estos cambios rítmicos y acentuales describen un esquema melódico que dota a los versos de Rivas de una musicalidad manifiesta. Por otro lado, la intervención de Leonor no interrumpe el flujo expositivo de D. Álvaro, de tal manera que: "si la poesía fuera música, fuera ópera, tendríamos aquí una simultaneidad de ejecución: tendríamos un dúo concertante" (Busquets 1989: 446). Aquí la voz de Leonor apenas es un susurro que pretende poner freno al torrente arrollador de su amante. Después de “¡Don Álvaro!” (v. 249) viene la afirmación esencial en la que se condensa el significado del amor en este drama expuesta por el protagonista: "Mi bien, mi Dios, mi todo" (v. 250). Un verso cuyas estructuras 
sintácticas repetitivas precipitan el curso verbal provocando un legato, a pesar del stacatto ocasionado por las comas. Una precipitación que desata de nuevo la euforia en los versos siguientes (vv. 251-255) produciendo una línea melódica ascendente-descendente gracias al encabalgamiento sostenido y al alargamiento de la curva sintáctico-melódica. Un ascenso tonal que culmina en el término "sol" (v. 253) para retornar a la tierra en la exclamación ponderativa “¡Prenda adorada!” con la que D. Álvaro califica a su amada.

Del análisis de este fragmento deducimos que Rivas tenía voluntad expresa de dotar a sus versos con modulaciones musicales producidas por el juego de los contrastes rítmico-melódicos que en aquellos se contienen. Este hecho no pasó desapercibido para Del Campo, quien supo ver en el texto del Duque de Rivas no solo su potencial escénico y dramático, sino sus esencias musicales.

Convencido nuestro autor de que el drama de Rivas contenía en sus versos los elementos musicales que él precisaba para componer su ópera, optó por la Jornada $\mathrm{V}$ del aquel como trama argumental para su drama lírico. Con esta decisión trasladaba a su ópera las escenas finales del texto teatral, justo las que concentran la acción en el episodio nuclear y más trágico, eludiendo con ello la dificultad que suponía elaborar la versión musical de un drama tan complejo. Así Del Campo sintetiza en un solo acto y dos cuadros el argumento de su ópera. En el primero de ellos nos presenta a D. Álvaro retirado en el convento franciscano de Los Ángeles, en la sierra cordobesa, lugar en el que expía sus culpas. En este marco físico tiene lugar su encuentro con D. Alfonso, hermano de Leonor, que viene a vengar las muertes que el protagonista provocó en su familia, por lo que el enfrentamiento entre ambos resulta inevitable. D. Álvaro acepta el duelo y en medio del lance, don Álvaro logra herir mortalmente a D. Alfonso, pero aparece por sorpresa D. ${ }^{a}$ Leonor, para intervenir en el duelo. D. Álvaro se alegra al saber que su amada vive aún y se halla cerca de él, pero cuando ella intenta socorrer a su hermano moribundo, éste extrae el puñal que se encontraba clavado en su pecho y la mata por considerarla cómplice de D. Álvaro antes de morir allí mismo. La muerte de D. ${ }^{\mathrm{a}}$ Leonor precipita la locura de D. Álvaro, que ahora se siente culpable de todas las muertes habidas que han ocurrido a su alrededor. Ante los monjes aterrorizados, D. Álvaro se suicida arrojándose desde un precipicio gritando “ ¡Soy un enviado del infierno, soy un demonio exterminador!"

Sobre este soporte argumental confecciona Conrado del Campo la partitura de El final de Don Álvaro, empresa en la que no sigue la línea estética modernista 
imperante derivada del impresionismo musical francés, capitaneada por Manuel de Falla y defendida a capa y espada por Adolfo Salazar, sino que apuesta por las prácticas basadas en la música de la segunda mitad del XIX dejándose influir por la herencia del arte musical wagneriano. Esta independencia de criterio fue la causa de que fuese injustamente olvidado por la historiografía española, pese a que: "Conrado del Campo, foi un dos músicos españois maís influentes e acticos durante o primeiro terxo do século $\mathrm{XX}$, cun catálogo moi nutrido que vai máis alá das 219 obras e no que toca practicamente todos os xénero, fois un dos representantes máis destacados dun estilo tardorromántico que se apoi en prácticas musicais propias da segunda metade do século XIX, moi influído por una herdanza de corte wagneriana" (Ferreiro 2017: 11). Esta insumisión a los cánones estéticos imperantes permite a Del Campo desarrollar el potencial lírico y escénico del Don Álvaro desde un enfoque marcadamente nacionalista, cumpliendo con ello uno de sus anhelos: establecer las bases de una ópera nacional como género musical inspirado en fuentes literarias propias frente al modelo operístico verdiano. Un rechazo hacia el paradigma verdiano que haría explícito el 6 de junio de 1932 en su discurso de ingreso en la Real Academia de Bellas de San Fernando:

\footnotetext{
$\mathrm{Y}$ es curioso en verdad ver cómo nuestros poetas románticos, que en el ambiente español bañaban sus pensamientos acudiendo a las puras fuentes del pasado, tradiciones, leyendas y romances históricos, en busca de elementos de inspiración para sus obras y logrando crear bajo el influjo animador de esos venerables testimonios del puro sentimiento de la raza obras como El Cristo de la Vega y Margarita la Tornera, Zorrilla; los Romances y Don Álvaro, el Duque de Rivas; no percibieran el profundo sentido, la ferviente corriente evocadora de fondo musical, la intensidad romántica que en su seno encerraban esas mismas tradiciones y desconocieran o, al menos, no se interesaran por el caudal de nuestras canciones, caminando en pos, cuando de música se trataba, de la melodía italiana, del corte, acento y expresión de la ópera romántica, sin advertir la oposición profunda que entre aquellas fuentes poéticas a que ellos acudían en busca de legítimas inspiraciones y el arte italiano existía. (Del Campo 1932: 10)
}

\section{De los postulados wagnerianos del drama lírico a las bases de la ópera nacional}

Una vez que Del Campo cuenta con lo que habría de ser el embrión del texto de El final de Don Álvaro se dispone a componer la partitura. Una tarea 
en la que sigue los pasos del arquetipo musical wagneriano para el drama lírico, por el que profesaba ferviente admiración. Un modelo que Del Campo conocía al haber leído los ensayos de Wagner, en concreto el titulado Opera und Drama (1850-1851) en el que el músico alemán determina la estética del drama a través de la música. En este ensayo Wagner establece una nueva forma de escribir los versos del libreto:

\begin{abstract}
A new form of verse-setting (Versmelodie) is outlined, in which the melody will grow organically out of the verse. It will use Stabreim (an old German verse form using alliteration) and a system of presentiments and reminiscenses, functioning as melodische Momente ('melodic impulses'); see Leitmotif. Only rarely will one voice serve as harmonic support for another; chorusesand other ensembles will be eliminated. Wagner's claim that the new ideas and techniques had 'already matured' within him before the theory was formulated something of an exaggeration, as is suggested by his willingness to adap the theoretical principles in the light of practical experience". (Millington et al. 2009: 8)
\end{abstract}

Esta nueva forma de concebir la escritura de los versos del libreto, según la cual la música debe surgir orgánicamente de estos, es justo lo que Del Campo encontró en las últimas escenas de la Jornada $\mathrm{V}$ del drama de Rivas. Esta es la razón por la que se decidió a componer El final de Don Álvaro siguiendo las pautas de wagnerianas, según los cuales: "the music drama was, of course, the genre evolved by Wagner as the ideal vehicle for reconciling symphonic principles with a literary and philosophical content" (Ibidem, 27) Es el drama lírico el género musical más adecuado, según Wagner, para conciliar los principios sinfónicos con el enfoque literario-filosófico del texto. Una conciliación que tan solo es posible cuando el texto y la música se fusionan de un modo indisoluble logrando que la ópera se constituya como una continuidad orgánica, en la que el uso de los impulsos melódicos denominados leitmotiven adquiere un papel relevante. Dichos impulsos son los responsables de armonizar los motivos dramáticos con las tonalidades musicales específicas. En suma, se trata de configurar un nuevo lenguaje musical con disonancias no resueltas y con el uso de secuencias musicales, amén de otras características propias del estilo wagneriano, como el uso de un elevado cromatismo y una pronunciada densidad orquestal. En este sentido, tal como precisa Mark Berry: 
Contrary to widespread opinion, Richard Wagner started off his career as the most revolutionary composer of the nineteenth century, not just in a musical sense but also in a more straightforwardly political manner [...] Wagner aimed not at a restoration of tragedy but rather at its renewal. His plans may be understood in terms of an abiding problem of modern political philosophy: how to reconcile the apparently idyllic communal integration of Hellenic life and the post-Classical or Christian conception of subjectivity. (Berry 2015)

Esta nueva manera de concebir el drama lírico es puesta en práctica por Del Campo en El final de Don Álvaro, pues en esta ópera se produce la presencia de los Leitmotiven o motivos recurrentes, aunque nunca utilizados de manera continua. De este modo dicho uso no resulta excesivo, al ser esta ópera una pieza breve en un acto lo que casi no permite recurrencias temáticas debido al escaso desarrollo de la acción. En todo caso estos motivos recurrentes se usan en esta pieza de un modo poético y evocador, tal como sucede con el tema de la pasión con que viven su amor D. Álvaro y D. ${ }^{\text {a }}$ Leonor. Dichos motivos no experimentan la transformación wagneriana, sino que se mantienen estables tanto en su perfil melódico como tonal.

Otro de los recursos wagnerianos que se aprecia en este drama lírico es su tendencia a una armonía divergente, en la que se debilitan las referencias tonales. Al mismo tiempo en el lenguaje armónico se percibe un uso constante de acordes de séptima disminuida y la ruptura de cadencias, lo que provoca una continua inestabilidad, que favorece la tensión dramática. Una tensión que se mantiene gracias al uso de texturas orquestadas muy densas, con un tejido contrapuntístico muy activo en todas las partes de la obra, en las que se produce una acumulación melódica y temática en vertical. Es este un rasgo propio de Conrado del Campo, debido a su formación como instrumentista de orquesta. En cuanto al tratamiento vocal: "este tiende a lo dramático, con papeles de gran resistencia en los que se incide en el canto sobre la zona de paso, tal como sucede en los protagonistas de El final de Don Álvaro" (Sánchez 2005: 769). Convencido Del Campo de que los postulados del drama lírico wagneriano son los más acordes con su modo de entender este género musical, vuelve a retomarlos en la composición de su segunda ópera, La leyenda del beso (1915), por lo que pasará a ser tildado por la crítica de "wagnerista reconcentrado", a tenor de los comentarios de la prensa tras el estreno de esta pieza; 
Conrado del Campo es un wagnerista reconcentrado, casi fanático del coloso germano. Fuera de él rechaza todo horizonte. De Wagner es el cromatismo que repetidas veces asoma en la escena de amor. De Wagner es la inflexible línea que permanece inmutable, pese a la multiformidad extrínseca de adorno musical. (Calvo Sotelo 1915)

Veamos, pues algunos ejemplos que ratifican la puesta en práctica de los dictados wagnerianos en El final de Don Álvaro. Ya en los primeros compases de la partitura recurre Del Campo al leitmotiven vinculado al tema de la pasión amorosa que D. Álvaro siente por D. ${ }^{a}$ Leonor:

\section{MUESTRA 1}

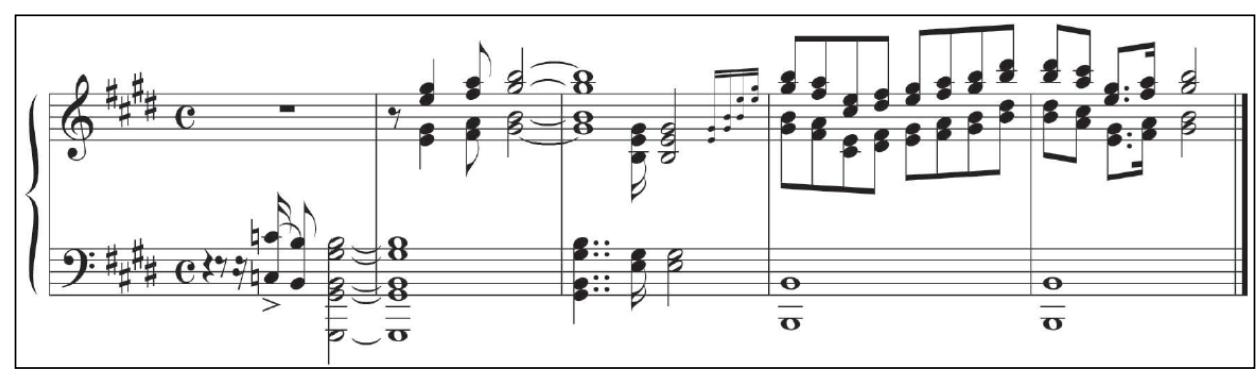

Ejemplo 1. Fragmento tomado de la copia efectuada por el autor que se cita del manuscrito original. (Sánchez 2010: 158)

Estos leitmotiven reaparecen en otros momentos significativos, como el del recuerdo de D. Álvaro por su amada:

\section{MUESTRA 2}

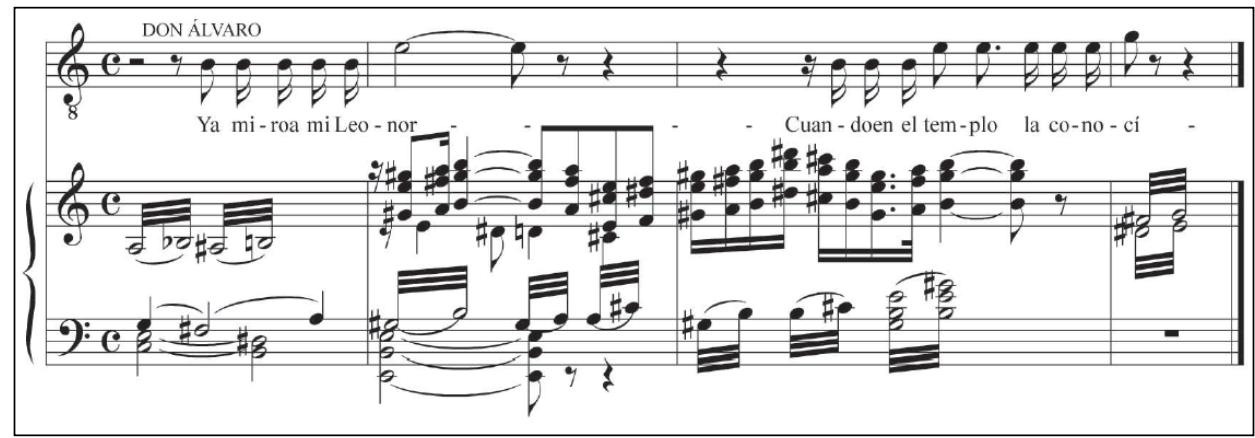

Ejemplo 2. Fragmento tomado de la copia efectuada por el autor que se cita del manuscrito original. (Sánchez 2010: 159) 
Y justo antes de la presentación de la propia Leonor en el segundo cuadro, cuando ella descubre el asesinato de su hermano:

\section{MUESTRA 3}



Ejemplo 3. fragmento tomado de la copia efectuada por el autor que se cita del manuscrito original. (ibidem)

En estos tres momentos el tema no experimenta variaciones y se presenta en la misma tonalidad de Mi Mayor. No menos wagneriano es el uso de las voces por parte de los personajes principales: $\mathrm{D}^{\mathrm{a}}$. Leonor (soprano), D. Álvaro (tenor), D. Alfonso (barítono). Y en el caso de los protagonistas: «ambos afrontan largos papeles, sobre líneas declamatorias donde debe destacar el uso continuo de la denominada zona de paso de la voz, a la manera de las voces wagnerianas» (Ibidem).

Sin embargo, Del Campo no se contentó con adoptar el modelo wagneriano al componer El final de Don Álvaro, sino que aprovechó el drama de Rivas para dotar a su ópera de un acento netamente español. A tal fin añadió al texto del Don Álvaro dos escenas propias del folklore hispano. Con esta aportación materializa dos de sus más claras pretensiones: de un lado, sentar las bases de la él denominaba "ópera nacional”; y, por otro, diferenciar su adaptación operística del texto de Rivas de la que en su día hiciera Verdi, pues si al genio italiano le atrajo:

No solo la fatalidad que presidía la vida de los personajes de La fuerza del sino, sino también la posibilidad de utilizar el trasfondo político de una obra que venía pintiparada a los nuevos aires del independentismo italiano, suscitado incluso por el consabido anagrama de su propio nombre (VERDI: Vittorio Emmanuele Re D'Italia). Sin olvidar el reclamo de una Andalucía dieciochesca en la que el indiano don Álvaro pintado por el duque de Rivas aparecía como un hombre duro y «muy echado adelante», que era además «el mejor torero que tiene España», y al que una gitana llamada Preciosilla le leía con donaire cervantino las rayas de la mano. (Egido 2010: 260) 
A del Campo le atrajo la idea de transformar la Jornada V de Don Álvaro en la escenificación de la quintaesencia del carácter patrio. A tal fin introduce un "canto de trilla" entonado desde la lejanía por un gañán, al final de la primera escena de su ópera, del que reproducimos unos compases:

\section{MUESTRA 4}



Ejemplo 4. Fragmento tomado de la copia efectuada por el autor que se cita del manuscrito original (Sánchez 2010: 157)

El propio D. Álvaro comenta al oír este alegre canto que vuelve al mundo real, alejándose por un instante de sus inquietudes. En este pasaje el lenguaje musical no es tan denso ni tan cromático como en otras escenas, pues el músico recurre a sonoridades más desnudas y a una armonización más diátonica de sabor modal, evitando la sensible, sobre un Sol mixolidio.

El segundo añadido es una cadencia andaluza que subraya el carácter regionalista de El final de Don Álvaro. Se trata de la aparición de unos pastores y de un coro popular que aparecen en medio de la sierra haciendo comentarios sobre Leonor, la misteriosa habitante de la ermita, en un pasaje construido sobre un ritmo ternario de claras resonancias españolistas. Pasamos a reproducir los compases 286-290, correspondientes a la citada cadencia ubicada también en la escena primera de la ópera por nosotros estudiada: 


\section{MUESTRA 5}



Ejemplo 5. Cadencia andaluza, escena I de El final de don Álvaro, compases 286-290 (Ferreiro 2017: 15)

Todos estos pasajes españolistas de carácter popular son destacados por el compositor Manuel Manrique de Lara, quien los destaca por encima del resto de la obra:

Sin embargo, en su hermosa obra yo prefiero aquellos otros, como el final del primer cuadro, como las escenas pastoriles del cuadro segundo, en que sobre la exquisita y magistral labor de la orquesta y la habilidosa intervención de las voces, se extiende un tenue velo de bucólica poesía. (Manrique de Lara 1911)

\section{Carlos Fernández Shaw (1865-1911) y su libreto de El final de Don Álvaro}

Tan pronto Conrado del Campo maduró la idea de componer una ópera basada en el Don Álvaro contactó con quien, a su juicio, era el más indicado para escribir su libreto: Carlos Fernández Shaw, que a la sazón era uno de los más prestigiosos libretistas del teatro lírico del momento. Procedemos, en primer lugar, a conocer las razones que avalan la notoriedad de este poeta por el que 
se decantó Del Campo. En un segundo momento analizaremos hasta qué punto el texto del libreto que se le encargó satisfizo los deseos de nuestro músico, sin cambiar las esencias del drama original. La elección de Fernández Shaw, a quien Del Campo conoció gracias a la mediación de Ruperto Chapí, no fue al azar. Tenía noticia nuestro autor del acierto literario de sus libretos para las obras de Chapí, tal es el caso de Las bravías (1896), zarzuela en un acto; La Revoltosa (1897); Margarita La Tornera (1909), ópera en un acto o El hijo del batallón (1898), zarzuela en tres actos, entre otras. Este éxito logrado por Chapí se debe, en gran parte, a contar con un libretista de la talla de Fernández Shaw. De la estrecha colaboración entre ambos "salieron a la escena madrileña algunas de las aportaciones de mayor calado en la historia de la zarzuela" (Gracia 1995: 231)

Sin embargo, y pese al papel imprescindible del libreto para que las óperas triunfasen, era práctica común a comienzo de siglo XX atribuir el éxito de las mismas al compositor y relegar al libretista a un segundo plano. Contra esta costumbre se reveló Fernández Shaw reivindicado la necesidad de equipar la importancia y dignidad de su trabajo al del autor de la partitura, y en consecuencia contar con los mismos derechos económicos y el mismo mérito artístico. Fernández Shaw fue un pionero en la defensa de los méritos del libretista. De ello nos deja constancia en uno de sus manuscritos titulado Los libros de ópera en español que se conserva en el Legado Fernández Shaw, Fundación Juan Mach, sin fecha ni destinatario:

\footnotetext{
Quizá me equivoque pero a mí se me figura, que consciente o inconscientemente, muchos autores rehúyen la tarea de escribir libros de ópera porque ven o creen ver que sus obras han de quedar forzosamente supeditadas a la del músico y oscurecida por ella. En mi humilde esfera de acción yo jamás he tenido en cuenta estas consideraciones que acaso califiquen algunos de tiquis miquis, pero comprendo que en otros muchos casos pueden ejercer un positivo influjo, dañino para la ópera nacional. El libro de ópera no es ya, como lo fue en otras épocas, un simple pretexto, sino parte importantísima de la obra total. No gana hoy los favores del público por esos mundos, ópera alguna que no tenga buen libro. Por otra parte, lo mismo en Francia que en Italia, y no hablo de otros países porque no sé exactamente lo que suceda en ellos, aunque supongo será lo mismo, poetas líricos de primer orden y autores dramáticos de los que figuran en primera línea componen y escriben muy a gusto libros de ópera que les proporcional a la vez mucho provecho y mucha gloria. Pero - justo es considerarlo -, sus poemas musicales son tenidos en mucho y los nombres de tales libretistas aparecen siempre con los de sus celebrados músicos, a un mismo nivel y no con visible situación de inferioridad. Aquí no hemos perdido aún las viejas costumbres. La ópera tal o cual es del maestro fulano o mengano, y a libretista que le parta un rayo (Fernández Shaw Signatura: CFS83O)
} 
Con similar contundencia se expresa para reclamar los derechos económicos del libretista. Lo hace en una comunicación dirigida a la Junta Directiva de una asociación que no se identifica ni se data:

\begin{abstract}
Los asociados que suscriben (a la Junta Directiva de esta Asociación) [...] Nos referimos al derecho que el autor del libreto, en una obra lírico dramática o cómico lírica, debe tener sin limitación alguna, sobre la letra cantable que sirva de base al maestro compositor para la creación de su obra musical. Dejando a un lado los rendimientos que la obra teatral produce, puesto que la ley y la costumbre de consumo establecen y fijan una perfecta igualdad de beneficios entre el autor o autores de la letra y el autor o autores de la música, quedan tres grandes aprovechamientos de la producción escénica, en los cuales, hoy por hoy, suelen beneficiar únicamente al compositor. Estas tres fuentes de ingresos son y las citaremos por un orden que pudiéramos llamar cronológico: las ediciones de canto y piano; las copias escritas o litografiadas de la parte musical y de las cantables que sirven en los teatros para los ensayos y representación de las obras, y la reproducción de trozos de las mismas (Ibídem:
\end{abstract} CFS-83C)

Estas reivindicaciones estaban justificadas, pues Fernández Shaw nunca renunció a escribir libretos con destacada calidad literaria. A esta impecable labor se refiere José Prieto Marugán cuando en relación con el libreto de El final de Don Álvaro señala que:

Hay que destacar la calidad literaria de la poesía de Carlos Fernández Shaw, infrecuente en libretos de ópera y con cierta complicación para ser entendida, al menos en esos tiempos. Si ya tiene dificultad leer alguno de estos versos y entender su significado, mucho más lo es entenderlo cuando son versos cantados. Se elogió el trabajo poético de Fernández Shaw sin considerar - como en otras ocasiones - si la adaptación era o no conveniente. (Prieto 2012: 248-249)

Por todo lo expuesto sabía Conrado del Campo que contar con Fernández Shaw como libretista para su ópera era garantía de éxito por lo que no dudó en requerir su colaboración. En la fluida correspondencia mantenida entre ambos queda patente que se entendieron a la perfección para sacar adelante un proyecto operístico del que hicieron causa común:

Mi querido amigo, en poder del Sr. Boceta se halla hace unos días la partitura terminada de El final de Don Álvaro, ya está acabada y con ella se ha ido para Madrid una gran 
suma de ilusiones, de esperanzas, con ella mis energías, mis esfuerzos, iquisiera que estas no fueran estériles y aquellos no se malogren entre el esplendor luminoso de nuestra sala de ópera! ¡Tantos planes, tantos proyectos arrastrarán consigo el fracaso de Don Álvaro! Confiemos en que el público habrá de ver en nuestra obra el propósito levantado de una labor de arte, la inspiración noble que nos guía, y usted sobre todo probado y sufrido compañero en esta larga lucha por nuestra ópera nacional y el ansia de liberarnos, por el esfuerzo de nuestra voluntad, de la esclavitud en la que yace nuestra ópera. (Heine 2002: 211)

Pasemos ahora a considerar los cambios que Fernández Shaw efectúa en el texto de Rivas para ajustarlo a las pretensiones de Conrado del Campo. En este análisis no entramos en la comparación entre el texto dramático y el libreto, pues ambos están concebidos como creaciones poéticas de distinto alcance. En el caso de El Don Álvaro los versos están compuestos para ser declamados, mientras que en El final del Don Álvaro se escriben para ser cantados. En otras palabras, Rivas dota a su obra con los ingredientes del drama romántico y Fernández Shaw tan solo se centra en la recreación escénica del desenlace del mismo. Lo que nuestro libretista pretende es dotar a la ópera de un apoyo textual sobre el que asentar los ritmos y cadencias de la partitura de Del Campo, la cual:

Se basa en el trabajo contrapuntístico y sus consecuencias armónicas por un lado, y por otro en la orquestación e invención de efectos sonoros novedosos. El contrapunto y la orquestación, sin descuidar la instrumentación, constituyen los parámetros que forman una unidad y están estrechamente unidos a la armonía, la cual por lo general se encuentra concebida horizontalmente, conforme a los principios estéticos de este compositor. (Ibidem: 111)

Para empezar Fernández Shaw recorta considerablemente el número de personajes que intervienen en la Jornada V del drama de Rivas: de un lado, elimina al Hermano Melitón, al viejo, al cojo, al manco, a la mujer; mientras que de otro, incluye a otros que no están en dicha Jornada: Curra, Nieves, Fuensanta, las cabreras y un Gañán. Del mismo modo, se salta las tres primeras escenas del texto original y comienza el suyo por la cuarta escena del texto de Rivas. Recortes y ajustes que responden a la intención de Del Campo de componer una ópera con tan solo dos Actos. 
(Jornada V, Escena IV de Rivas)

El teatro representa la celda de un franciscano.

Una tarima con una estera; un vasar con una

Jarra y vasos; un estante con libros; estampas, disciplinas y cilicios colgados. Una especie de oratorio pobre, y en una mesa, una calavera; DON ÁLVARO, vestido de fraile, aparece de rodillas en profunda oración mental.

\author{
HERMANO MELITÓN (Dentro) \\ ¡Padre! ¡Padre!
}

DON ÁLVARO (Levantándose)

¿Qué ofrece?
(Acto I, Escena I, de Fernández Shaw)

Celda de un fraile franciscano, en el convento de Los Ángeles. A la izquierda una tarima, con una estera; un vasar con una jarra y vasos, un estante con libros, estampas, disciplinas y cilicios colgados. En el fondo una ventana con sus hojas de madera cerradas por cuyos resquicios pasa luz del día. A la derecha de la ventana una especie de oratorio pobre, en el que lucen dos lámparas, que alumbran la escena. (Coro de religiosos, dentro y hacia derecha) Don Álvaro: Me dejad P. Guardián: Nunca, nunca (Fernández Shaw 1911: 9)

Entre, hermano Melitón (De Rivas [1835] 2010: 170)

En la primera escena el libretista suprime el diálogo entre D. Álvaro y el Hno. Melitón y nos presenta la conversación del protagonista con el P. Guardián, con lo que encamina la acción de su texto hacia el trágico desenlace final: la imposibilidad de que D. Álvaro logre el amor eterno de Leonor.

Otro cambio significativo es el que se refiere al uso de la estrofa que predomina en ambos casos. Rivas se decanta por la redondilla, mientras que el libretista se inclina por la silva. El primero recurre al metro corto y a la rima pegadiza y de fácil memorización para los actores, pero Fernández Shaw busca el verso largo, la prolongación de la frase y la adecuación de sus acentos y el ritmo a la estructura musical de la partitura.

EJEMPLO 2

(Jornada V, Escena V, de Rivas)

¿Quién podrá ser?... No lo acierto.

Nadie, en estos cuatro años,

que huyendo de los engaños

del mundo, habito el desierto,
(Acto I, Escena I, de Fernández Shaw)

P. Guardián: ¡Por piedad!

D. Álvaro: (exaltándose por momentos)

Y luego

los campos miro de la grande Italia; 
con este sayal cubierto, ha mi quietud disturbado.

¿Y hoy un caballero osado

a mi celda se aproxima?

¿Me traerá nuevas de Lima?

¡Santo Dios!... ¡Qué he recordado!

(Ibidem, 172) donde busqué a la muerte, que me diera Consuelo, al fin, en la lucha memorable $\mathrm{Y}$ allí don Carlos, que a mis ojos surge como espectro del odio, vengativo.

$\mathrm{Y}$ de nuevo mis manos, ¡oh, mis manos! tintas en sangre de los Vargas (Fernández Shaw 1910:11)

En cuanto a los episodios de corte popular, el libretista recurre al romance, estrofa que responde al gusto de Conrado del Campo por los elementos populares y tradicionales que vinculen su ópera con las costumbres hispanas.

EJEMPLO 3

(Acto I. Escena I. Canto de trilla.

Voz de un gañán que llega por la

izquierda un tanto lejana)

«Sobre las eras corro

por la mi yegua bruna;

sobre las rubias ondas

de las espigas rubias.

¡Hala, mi yegua dócil!

¿Que las espigas crujan!

P. Guardián: En las eras vecinas

El canto suena de la alegre trilla.

D. Álvaro: Canto de trilla alegre, sensaciones del mundo me devuelves.

(Ibidem , 10)
(Acto II, Escena I. Canto de cabreras:

Curra, Nieves y Fuensanta. Coro)

Fuensanta: Si en peligro se mirase, con el son de su campana de sus cuitas avisase.

Curra: ¡Qué campana tan cristiana! Fuensanta: ¡Solo en riesgo capital1 Curra: ¡Dios le libre de que acuda, con terror a la señal! [...]

Nieves: La gente moza

que en domingo se alboroza

- ve cual bulle por allí -

si en sus jiras se aventura

por aquestos andurriales

templa el canto.

Escena II

Coro: Canciones de la sierra, serranas hermosísimas ¡sonad, sonad!

Cual otros tantos pájaros que crucen por el aire, ¡volad, volad, volad! (Ibidem, 19) 
Sin embargo, la aportación más señalada es la recuperación del trágico final del Don Álvaro. que Verdi modificó en su versión de 1869 de La forza del destino:

EJEMPLO 4

(La forza del destino (1862) Acto IV

Escena IX)

GUARDIANO: Gran dio!...sangue!.....cadaveri! La donna penitente!

TUTTI: $\quad$ Una donna!...Cielo!

GUARDIANO: Padre Raffaele.

ALVARO:

(dall'alto della rupe)

Imbecille, cerca il padre

Rafaele...

Un inviato dell' inferno son io.

MELITONE: L'ho sempre detto...

¡Misericordia!

(Cuadro. Relámpago vivísimo

ALVARO: Apriti, o terra,

m'ingoli l'inferno!.....precipiti

il cielo...pera la razza umana...

(ascende piu alto e si precipita in

un sottoposto burrone)

TUTTI:

Orrore!.....Orrore! (Verdi 1862: 50)
(El final de Don Álvaro (1910) Acto II

Escena última)

Dña. Leonor, P. Guardián, Coro: ¡Jesús!

Álvaro: ¡Abismos

del reino de Luzbel, abrid las fauces,

y en ellas caiga! ¡Rásgense los cielos!

¡Quebrántense los montes! ¡iExterminio!!

¡Destrucción!

(Precipitase desde lo alto de la montaña)

D. ${ }^{a}$ Leonor, P. Guardián, Coro:

¡Misericordia! ¡¡Oh, Dios!!

que inunda la escena, hasta que cae el

telón por completo, de un resplandor

infernal) (Ibidem, 28)

\section{Los ecos de El final de Don Álvaro en la prensa de la época}

El hecho de que El final de Don Álvaro se estrenase en los últimos días de la temporada operística de 1910-1911, que contase con actores de segunda fila y que se hiciera tras escasos ensayos hacía presagiar lo peor. Sin embargo, y pese a las crónicas que ponían en tela de juicio el tratamiento vocal que el compositor asignaba a los cantantes en esta pieza, la acogida tanto del público como de la crítica fue mejor de lo que cabía esperar de acuerdo con las dificultades señaladas:

La orquestación en el segundo acto es magnífica y resulta de una labor de gran maestro, poniendo Del Campo de manifiesto su gran talento musical: si las voces las tratara con el 
acierto que lo hace en la orquesta, mucho mayor éxito le hubiera acompañado. La tesitura del tenor y del soprano es demasiado aguda, y sobre todo teniendo que pronunciar palabras a tan altas voces; así es que pocos artistas podrán registrar tales tesituras, y eso principalmente será la causa mayor para que su ópera no tenga tantos admiradores entre los cantantes. ( $E l$ Debate 5.3.1911)

la mayor parte de las críticas y reseñas hacen alusión al éxito de la obra, subrayando aspectos concretos de la ópera que, a juicio del comentarista, son dignos de mención. Tal es el caso de Manuel Manrique de Lara, quien repasa todos los elementos que contribuyeron a que el público emitiese un dictamen favorable:

La sentencia del público a la ópera de Fernández Shaw y Conrado del Campo no pudo ser anoche más favorable. Muchas veces durante la orquestación, resonaron los aplausos, nutridos, entusiastas para el ilustre compositor de El final de Don Álvaro; e igualmente a la conclusión de los actos, tuvo que comparecer muchas veces en el proscenio rodeado de los afortunados intérpretes. [...] El estilo de la nueva ópera es de una gran elevación. En todo instante, a través de la acción, fulgura intensamente el propósito de que la labor de la orquesta haga revivir el drama. Los momentos de pasión intensa, tan frecuentes en el hermoso poema del Duque de Rivas, que ha recibido del insigne Fernández Shaw estructura apropiada, digna de su admirable pluma, a la realización musical, están tratados por Conrado del Campo con expresión de avasalladora violencia. Sin embargo, en su hermosa ópera, yo prefiero aquellos otros, como el final del primer cuadro, como las escenas pastoriles del cuadro segundo, en que sobre la exquisita y magistral labor de la orquesta y la habilidosa interpretación de las voces, se extiende un tenue velo de bucólica poesía. Las mayores novedades y audacias en la invención melódica, los alardes más primorosos de fragmentación en la técnica orquestal, parecen en ellos espontáneas manifestaciones del pensamiento íntimo y la única forma adecuada a la realización de las ideas. (El Mundo 5.3.1911)

\section{En términos parecidos se expresa el cronista de El Heraldo de Madrid,} aunque no desciende a un análisis tan pormenorizado:

Grande, profunda satisfacción tuvimos al ver que aplaudían con entusiasmo a Conrado del Campo sobre la escena del Teatro Real. Conrado del Campo es un músico de gran talento y además un hombre bueno. Por el arreglo literario no ha de olvidarse al ilustre Fernández Shaw. [...] Muy bien y con gran voluntad Villa al frente de la orquesta, en la que tocaba el autor en el estreno de su obra. (El Heraldo de Madrid 5.3.1911) 
De similar alcance es el análisis acometido por el analista de El País:

El público, como era de esperar, se rindió a la evidencia, y dispensó al drama lírico de Fernández Shaw y Conrado del Campo una acogida calurosa y entusiasta, reconociendo a la vez que también en España hay quien sabe componer óperas. [...] La interpretación estuvo muy acertada, sobre todo teniendo en cuenta la precipitación con que se ha ensayado la ópera. Conrado del Campo y los intérpretes de El final de Don Álvaro, tuvieron que presentarse muchas veces en escena, siendo aclamados por el público. Enhorabuena a todos. (El País 5.3.1911)

\section{Conclusiones}

A la largo de la presente contribución hemos demostrado que el tándem profesional integrado por Conrado del Campo y Carlos Fernández Shaw supo plasmar con acierto en El final de Don Álvaro todo su saber musical y literario. En esta pieza se concretan los tres elementos que singularizan a las primeras óperas de Conrado del Campo: su apuesta por el wagnerismo musical como modelo operístico, su opción por los elementos tradicionales del drama romántico y su indiscutible empeño por crear una ópera nacional. Estas son los rasgos que definen el formato musical de las primeras óperas de Del Campo.

La presencia y el alcance de los mismos en la ópera aquí estudiada es lo que hemos demostrado en el presente artículo. La habilidad y el ingenio musical de Del Campo y la acertada labor de Fernández Shaw como libretista dan a luz una ópera de singular relevancia, cuyas virtudes son descritas por Joaquín Fesser en el siguiente comentario:

La factura, el trabajo armónico y melódico, el trato de las voces, el color instrumental, están hechos con entera libertad, sin una sola concesión a lo convencional ni a lo rutinario. $\mathrm{Su}$ orientación es la de Wagner y sus sucesores, sin el menor servilismo ni sectarismo, sin asomo de imitación o de plagio. La melodía y la sinfonía son continuas, residiendo en esta última el comentario anímico íntimo, y en aquella la expresión lírica verbal siempre o casi siempre declamada, sin cuadraturas, sin moldes, sin estrofas, sin obligadas simetrías ni melismas románticos. (El Correo 5.3.1911)

Queda claro, por tanto, que Del Campo plasmó en El final de Don Álvaro sus deseos de componer un drama lírico que, siguiendo las pautas musicales 
del último romanticismo de herencia wagneriana, se convirtiera en una obra sinfónica representativa de lo que él entendía por ópera nacional. Este interés por promocionar un canon operístico español estará en el origen del resto de sus óperas: La tragedia del beso (1911), El Avapiés (1919), Fantochines (1923), La malquerida (1925) y Lola, la piconera (1950).

Esta es la concepción del drama lírico que pone en práctica Del Campo en El final de Don Álvaro. Se trata de un modo de entender el teatro lírico en el que el texto literario del drama romántico y la partitura de la ópera de inspiración tardorromántica tienen elementos en común. Una concepción que para David Ferreiro, conlleva "su participación activa en la construcción de esa "otra" musical española (Ferreiro 2018: 158) Literatura y música van de la mano cuando el mensaje que se pone sobre las tablas es el mismo, aunque los lenguajes que lo expresan sean distintos. En definitiva, de lo que se trata es de llegar al público e influir en su estado de ánimo, provocando en el espectador nuevas sensaciones y nuevos sentimientos, bien por medio de la declamación de los versos o a través del canto de los mismos. Lo que Rivas consigue mediante la acertada interpretación de los actores que ponen voz a los personajes de su drama, Del Campo lo logra por medio del exitoso canto de los tenores, barítonos y bajos que dan vida a su partitura.

\section{Bibliografía}

BARBA, Marina (2013). La música y el drama romántico español (1841-1844). Tesis doctoral Universidad Complutense de Madrid.

BERRY, Mark (2015). "Richard Wagner's revolution: music drama against bourgeois opera", Focal Blog,April, 8, <www.focalblog.com/2015/04/64108>.

BUSQUETS, Loreto (1989). "Estructuras musicales del 'Don Álvaro"', Revista de Literatura 102, 433-461.

CALVO SOTELO, José (1915). El Debate, 19.05.1915.

DEL CAMPO, Conrado (1911). "Estreno de esta noche". España Nueva, 04.03.1911.

DEL CAMPO, Conrado (1911). "Impresiones del autor". Revista Musical, 3, 1: 9.

DEL CAMPO, Conrado (1932). "Importancia social de la música y la necesidad de insistir en su cultivo en España”, Discursos leidos ante la Real Academia de Bellas Artes de San Fernando. Discurso de ingreso (06.06.1932). Academia de Bellas Artes de San Fernando, Madrid, 1932. 
DEL CAMPO, Conrado (1910). "Carta de Del Campo a Carlos Fernández Shaw", La saga Fernández Shaw y el teatro lírico. Fundación Juan March (Madrid: 21.09.1910). Código; CSS-AE-XIX.32.

DEL CAMPO, Conrado (1910). "Carta de Del Campo a Carlos Fernández Shaw", La saga Fernández Shaw y el teatro lírico. Fundación Juan March (Madrid: 31.02.1910). Código: C-XIV-31.

DEL CAMPO, Conrado (1910). "Carta de Del Campo a Carlos Fernández Shaw", La saga Fernández Shaw y el teatro lírico. Fundación Juan March (Madrid: 14.05.1910). Código: C-XIV-29.

EGIDO, Aurora (2012). "Las trampas de la libertad en La fuerza del sino y La forza del destino". Revista de Literatura 147 (Madrid: 2012): 249-276.

EL CABALLERO DEL CISNE (1911). "Los estrenos de anoche. Teatro Real". El final de Don Álvaro, El Debate, 05.03.1911.

E. L. G. (1911). "El estreno de anoche". Teatro Real. El final de Don Álvaro, El País, 05.03.1911.

FERNÁNDEZ SHAW, Carlos (1911). El final de Don Álvaro. Drama lírico en dos actos. Imprenta G. Velasco, Madrid, 8-9.

FERNÁNDEZ SHAW, Carlos. "Los libros de ópera española", La saga Fernández Shaw y el teatro lírico. Fundación Juan March (Madrid). Código: CFS-830. FERNÁNDEZ SHAW, Carlos. "Los asociados que suscriben”, La saga Fernández Shaw. Fundación Juan March, Madrid, Signatura: CFS-83C.

FERNÁNDEZ SHAW, Carlos. Shaw y el teatro lírico. Fundación Juan Mach, Madrid. Signatura: CFS-83-C.

FERREIRO CARBALLO, David (2017). “A teoría de tópicos musicais: un exemplo de aplicación na obra lírica de Conrado del Campo (1878-1953) e as suas posibilidades para a música galega". CUT TIME, Revista de Musicas do CMUS Profesional de Vigo 1: 8-21.

FERREIRO CARBALLO, David (2018). "Spanish opera at the crossroads: Conrado del Campo's El fin de Don Álvaro". Abstract, MMRC, University of Kansas, (Kansas, 21-22, September, 2018).

FERREIRO CARBALLO, David (2018). "La identidad lírica de Conrado del Campo en los retablos de Víctor Espinós". Cuadernos de Música Iberoamericana 31: 157-180.

FESSER, Joaquín (1911). El final de Don Álvaro, El Correo, 05.03.1911.

GRACIA IBERNIS, Luis (1995). Ruperto Chapi. Instituto Complutense de Ciencias Musicales, Madrid, 231.

HEINE, Christiane, (2002). "El magisterio de Conrado del Campo en la Generación del 27: el caso de Salvador Bacarisse y Ángel Martín Pompey", 
en Música española entre dos guerras (1914-1945). (Ed. Javier Suárez Pajares). Granada: Archivo Manuel de Falla. 99-13.

MANRIQUE DE LARA, Manuel (1911). El final de Don Álvaro, El Mundo, 05.03, 1911.

MARTÍNEZ RUIZ, José (1916). "Rivas y Larra". En Razón social del Romanticismo en España. Madrid: Renacimiento.

MILLINGTON, Barry et al. (2009). "Zurich Essays", Grove music on line, Wagner family 2009. https://doi.org/10.1093/gmo/9781561592630.article.29760.

PRIETO MARUGÁN, José (2912). El teatro lírico de Carlos Fernández Shaw. Madrid: Ediciones Orto.

SAAVEDRA, Ángel de (2010). Don Álvaro o la fuerza del sino. Alberto Sánchez (ed.). Madrid: Cátedra.

SÁNCHEZ, Alberto (2010). "Introducción". Don Álvaro o la fuerza del sino, Duque de Rivas. Madrid: Cátedra.

SÁNCHEZ SÁNCHEZ, Víctor (2010). "Resonancias tristanescas en la ópera española: wagnerismo en las óperas de Conrado del Campo". Anuario Musical 65, 145-170.

SÁNCHEZ SÁNCHEZ, Víctor (2005). "Análisis de las primeras óperas de Conrado del Campo: entre Wagner y el nacionalismo". Revista de Musicología 28, 764-773.

VERDI, Giuseppe (1862). La forza del destino. Libretto in quattro atti, di J. M. Piave. Milano, Regio Establecimiento.

WAGNER, Richard. 1984 (1852). "Opera und Drama”. Klaus Kropfinger (ed.). Stuttgart: Reclam. 